\title{
Fighting Intrusive Thoughts Using Podcasts: A Strategy for Effective E-Learning
}

\author{
Susan Smith Nash, \\ Excelsior College, Albany, NY, USA
}

susan@beyondutopia.com

\begin{abstract}
Delivering course content via portable/mobile audio players can be a part of an effective selfregulatory strategy that also accommodates multiple learning styles while overcoming intrusive thoughts and the anxiety that accompanies them. As a result, academic performance can improve, while increasing self-concept and self-efficacy. Preliminary results of a literature search tracing the impact of intrusive thoughts on performance and a survey of students in extreme conditions where intrusive thoughts are common, suggest that audio downloaded via podcast and played on mobile players can be an effective strategy for combating intrusive thoughts. The combination of surveys and published research also suggested that further studies are warranted in order to explore the most appropriate podcast-based solution to numerous varieties of negative cognitive and emotional responses.
\end{abstract}

Keywords: e-learning, instructional strategies, mp3, podcasts, cognitive interference, intrusive thoughts, multiple intelligences, attention principle, online courses, learning outcomes, new technologies, new content delivery methodologies, RSS, iPod, media player, e-learning in extreme conditions, anxiety, self-regulation, self-efficacy

\section{Course Content as Audio Files Delivered via Podcasts}

To accommodate learners' diverse learning styles, online courses often include course content in multiple modalities. In this case, such delivery format includes text, audio, video, and graphics synched with text and audio.

\section{Podcast Technology and E-Learning}

A podcast consists of an audio file, usually in mp3 format, which is distributed through the internet via "syndication." Syndication is accomplished through a computer program that disseminates the files to others, and which allows the automatic update and retrieval when new files are posted.

Briefly stated, the procedure is as follows: a podcaster records an mp3 file, uploads it to a space

Material published as part of this publication, either on-line or in print, is copyrighted by the Informing Science Institute. Permission to make digital or paper copy of part or all of these works for personal or classroom use is granted without fee provided that the copies are not made or distributed for profit or commercial advantage AND that copies 1 ) bear this notice in full and 2) give the full citation on the first page. It is permissible to abstract these works so long as credit is given. To copy in all other cases or to republish or to post on a server or to redistribute to lists requires specific permission and payment of a fee. Contact Publisher@InformingScience.org to request redistribution permission. on the server, and then creates a script in which the URL of the podcast location is enclosed. A subscriber encodes the $\mathrm{xml}$ script in a website so that whenever an update of the "feed" is posted, if he or she is logged in, the podcast automatically downloads to his or her computer via the Internet. Alternatively, a person wishing to subscribe to podcasts may use an "aggregator," which is a ser- 
vice that allows an individual to subscribe to multiple feeds.

A podcast is different from a simple audio file. What differentiates a podcast from an audio file is the fact that a podcast is actually an entire bundle of automated services, while an audio file is simply the file.

A podcasting program will:

1. distribute audio files to multiple locations;

2. allow users to simultaneously subscribe and then view descriptions in a single location (the aggregator site);

3. distribute files simultaneously to multiple users, and to automatically send updates;

4. download easily to media players, including smartphones, which enables a user to listen to the audio file while away from his/her computer.

Audio files which have been distributed as podcasts are popular because of the following reasons:

1. the files automatically download to portable media players;

2. one can use many different types of plug-ins, which allows the files to play on many different platforms;

3. it is fast and convenient, particularly since the audio files have usually been optimized for speedy download and smooth play;

4. many different devices can be accommodated, ranging from iPods and smartphones, to Xbox 360-generation video game players;

5. files are available "on demand" and in a portable mode, which allows for very convenient listening.

Users tend to listen to audio files that have been distributed and downloaded via podcasts while they are at work, at home, and traveling (Leaver, 2006). The mode is spontaneous and "mobile," which is very appealing to individuals whose learning styles tend toward audio rather than textual or visual.

\section{E-Learning in Extreme Conditions: Distractions and Intrusive Thoughts}

While the traditional classroom can be a place where learners can engage in conversations, debates, and non-verbal transactions, thus keeping unwanted mental intrusions at bay, the online or distance environment can function in precisely the opposite way and actually create an environment that triggers intrusive thoughts. Social isolation, a lack of engagement with a community of practice, and a highly text-based or visual learning environment leaves the auditory channels unused, and it keeps the individual from being fully engaged with respect to multiple learning styles. Further, any anxiety produced by the isolation, or frustration due to ambiguities in expectations and performance can even trigger unwanted mental intrusions. The undesired thoughts can spark a chain reaction of cause-and-effect responses to the intrusive thoughts as the individual tries to combat them, or feels anxiety about experiencing them.

What are intrusive thoughts? Intrusive thoughts are unwanted mental intrusions that are often disturbing and result in anxiety. According to the DSM-IV, intrusive thoughts or unwanted mental intrusions can be caused by or accompany a number of psychological conditions, including anxiety, obsessive-compulsive disorder, paranoia, grief, post-traumatic stress disorder, and schizophrenia. 
However, it is not necessary to have a severe psychological malady to suffer from unwanted mental intrusions. Anything that causes anxiety, including performance anxiety can result in intrusive thoughts. Other intrusive thought triggers include family discord, traumatic incidences, workrelated worry, and social pressure.

\section{Previous Work: Toward an Understanding of Intrusive Thoughts and Effective Strategies to Facilitate Learning in a Distance-Learning Environment}

\section{Finding}

Strauss (1969) and others suggest that intrusive thoughts (even auditory hallucinations) are a normal psychological phenomenon which fall well within the range of ordinary human experience. Nevertheless, the disturbing nature of the thoughts, coupled with the fact that they are unwanted, lead to negative beliefs about the thoughts (Posey \& Losch, 1983; Slade \& Bentall, 1988). Individuals begin to be concerned about the fact that they are having intrusive thoughts, even hearing voices. They may start to have a negative belief about themselves, and develop a negative self-concept (believing themselves to be "crazy" when in fact the experiences they are having could be well in range of the expected, given the nature of the environment and stress).

\section{Podcast-focused solution}

Listening to course content via a portable player can allow an e-learner to maintain focus and to continue to make progress in the course. Making progress can help bolster an e-learner's sense of self-efficacy. Listening to the course content, then sharing thoughts with others can also allow him or her to feel a part of a learning community and satisfy needs for affiliation.

\section{Finding}

Intrusive thoughts can be exacerbated by negative beliefs about intrusive thoughts, as well as negative beliefs about oneself in response to thoughts (Sarason, Sarson, \& Pierce, 1990; Slade \& Bentall, 1988). Ironically, thought-control strategies often backfire, and engender or propagate more intrusive thoughts, leading to unwanted intrusive thoughts about the unwanted intrusive thoughts; or "meta-worry" about worrying. When accompanied by stress and worry, negative self-beliefs and intrusive thoughts constitute cognitive interference (Sarason, 1984) and can adversely affect performance.

\section{Podcast-focused solution}

The important action here involves breaking the chain of negative beliefs, and to stop propagating negative thoughts. Listening to an audio file downloaded via podcast and available "on demand" when the bad thoughts strike could be a good line of defense.

\section{Finding}

Intrusive memories can be described as visual, auditory, or cognitive recall that occurs at unexpected times in settings that are unrelated to the topic of conversation, or the activity that is being engaged in (Brewin, Christodoulides, \& Hutchinson, 1996). Intrusive memories are different from intrusive thoughts in that the memories are of specific events, places, or times that occurred in an individual's experience, whereas intrusive thoughts can be completely unrelated "clang" associations, which could also be characteristic of organic thought disorder (schizophrenia, etc.). 


\section{Podcast-focused solution}

Because intrusive memories may influence the individual's emotions, it is important to give students strategies for keeping focused on the task at hand. Substituting audio can be a way to keep individuals from having negative emotions act as a barrier to persistence. Narrative structuring, which involves positive self-talk about the nature of the auditory hallucinations or intrusive thoughts, has been shown to help place the presence of the intrusions within a normalizing framework (Smyth \& Pennebaker, 1999; Smyth, True, \& Souto, 2001). Auditory hallucinations are, by definition, unwanted and intrusive (Morrison, Haddock, \& Tarrier, 1995) and they tend to generate anxiety, fear, and low worth. However, having a tactic for combating the intrusions can assuage the negative emotions, can help develop a positive self-image. It can also keep a negative self-image from manifesting itself.

\section{Finding}

S. Cartwright-Hatton and A. Wells (1987) found that there is a relationship between worry and negative beliefs about intrusive thoughts. This translates to a fear of intrusive thoughts that can be, in essence, paralyzing. However, patterns of intrusive thoughts vary. The length of the thought and the success of the intrusive thought in disrupting one's thought patterns can range from mildly distracting to profoundly disruptive. If the learner suffers from a pre-existing psychological condition such as post-traumatic stress disorder (PTSD), the intensity and duration of intrusive thoughts can be severe, depending on the level of severity of PTSD. (Chung, Dennis, Easthope, Farmer, \& Werrett, 2005; Gaskell, Wells, \& Calam, 2001). Further, one must consider environmental factors. If an individual is in an environment that contains intrusive thoughtprovoking triggers / stressors, then environmental changes are more likely to be effective in controlling intrusive thoughts. The podcast can mitigate the impact of the environment.

\section{Podcast-centered solution}

An effective strategy for breaking the cycle of intrusive thoughts is to have a method for intervening, of countering the thoughts with cognitive engagement. The intrusive thoughts can be minimized or eliminated by focusing and maintaining attention on a cognitively engaging activity such as listening to a podcast. However, if the intrusive thoughts occur because of conditions such as obsessive-compulsive disorder (Salkovskis, 1985), generalized anxiety disorder, or PTSD, podcast-based intervention strategies must be applied in a systematic manner in order to maximize the possibility of positive operant conditioning (Sarason, 1988; Sarason, Sarson, \& Pierce, 1990).

\section{Finding}

M. Chung et al. (2005) found that the number and intensity of intrusive thoughts suffered by those diagnosed with post-traumatic stress disorder (PTSD) is directly related to the intensity of the traumatic incident. The result is cognitive interference (Sarason, 1984) and it directly affects performance on standardized tests. Chung, et al (2005) found that the individual's age made no difference in the nature of the intrusive thoughts. Young and elderly alike experienced similar levels of intrusive thoughts, depending on the nature of the traumatic incident that led to the intrusive thoughts. Thus, extremely traumatic events are good predictors of the presence of intrusive thoughts, and it can be assumed that anyone who has experienced violent, traumatizing, disturbing incidences will possess a certain likelihood of having unwanted mental intrusions, regardless of age. 


\section{Podcast-centered solution}

A preliminary screening to determine if individual e-learners have experienced traumatic events could help identify individuals who could benefit from podcast-delivered content. Because a traumatic event can be accompanied by intrusive thoughts (Pennebaker, 1993; Pennebacker \& Beall, 1986; Pennebaker, Mayne, \& Francis, 1997), and the event is then followed by efforts to inhibit the thoughts, performance can be impacted in a negative way (Sarason et al., 1990). The podcast may help minimize the expenditure of energy to control or inhibit thoughts. However, it may actually act as an additional distracting element if the strategy is not employed in a way that focuses on desired learning outcomes.

\section{Finding}

J. Walker and J. Boyce-Tillman (2002) examined the role of focused concentration and auditory channels in self-regulation in cases where children suffered from anxiety. Specifically, they studied the impact of music lessons and whether or not the children were able to develop self-

regulatory strategies that involved a combination of auditory and kinaesthetic engagement. Kendall (1985) and Kendall et al. (1992) have found that both teenagers and children exhibit behavior which suggests that they engage in generating set patterns of thought designed to suppress the emergence of intrusive thoughts.

\section{Podcast-centered solution}

Because the technique of using generated thoughts to fight unwanted thoughts is common among teenagers and children, the technique of using a podcast to channel thoughts is not an alien one. There is a higher likelihood of success because the technique is familiar.

\section{Preliminary Research: Intrusive Thoughts as a Barrier to Persistence for Students in Distance Courses}

The goal of a study of deployed military students working under harsh conditions where they reported having unwanted intrusive thoughts was to determine (a) whether or not individuals used audio recordings downloaded via podcasts onto portable players; (b) whether they experienced unwanted intrusive thoughts; and (c) whether they used audio to focus their thoughts. The preliminary questionnaire was administered to 85 students who had been studying in conditions likely to give rise to intrusive thoughts.

The survey was administered in the summer of 2005 to a total of 85 active-duty military students.

In addition to asking about the perceived efficacy of audio in controlling intrusive thoughts, the students were also surveyed to find out which aspects of an e-learning program were most valued, and the impact that being in harm's way or under deployment stress has on having a successful educational experience.

There were numerous findings that related to delivery, access, and content of online courses. In terms of psychological barriers to persistence, perhaps the most surprising finding was that fully $50 \%$ of respondents reported being troubled by unwanted intrusive thoughts.

Further, many of the deployed military members who were surveyed reported that they took courses to "keep their mind off" what they were doing, and yet, reading and concentration were negatively impacted by the intrusive thoughts, and the energy expended in combating them.

Eight percent of the respondents reported that they used music and audio to help keep them focused or to relax them. In addition, many of the deployed military students reported listening to 
books on tape and downloaded mp3 audio recordings of popular works such as The DaVinci Code.

While only limited sections of course content were available via downloadable mp3 file, the general reaction to it was favorable. It is recommended that course content be available in both modalities - text and audio - and that the patterns and preferences of each be studied, and tracked with self-identified learning preferences or styles.

\section{Recommendations}

The preliminary survey of students, combined with the literature search that was coupled with proposed podcast-centered solutions, leads to the following suggestions for further study:

1. Instructional content in an audio format delivered via podcast can be an effective "any time, any place" on-demand way for learners to access content. Further studies should focus on how to best utilize the content to combat intrusive thoughts, which can be unpredictable and can occur (likewise) "any time and any where".

2. If the learner becomes aware of when intrusive thoughts are occurring and can utilize a strategy of focusing attention on alternative stimuli (audio) rather than trying to block out the thoughts by generating thoughts in response, performance in a course may be positively impacted (rather than negatively impacted, which happens when a learner tries to suppress or inhibit thoughts by himself or herself). Future studies should focus on how to maximize self-regulation tactics using podcasts.

3. Successful intervention and control of intrusive thoughts by using audio content can help develop the learner's belief in being able to succeed and achieve learning goals, and perform desired outcomes. Investigations should focus on whether learner self-efficacy can be enhanced by means of this technique.

\section{References}

Brewin, C. R., Christodoulides, J., \& Hutchinson, G. (1996). Intrusive thoughts and intrusive memories in a nonclinical sample. Cognition and Emotion, 10(10), 107-112.

Cartwright-Hatton, S., \& Wells, A. (1997). Beliefs about worry and intrusions: The metacognitions questionnaire and its correlates. Journal of Anxiety Disorders, 11, 279-296.

Chung, M. C., Dennis, I., Easthope, Y., Farmer, S., \& Werrett, J. (2005). Differentiating posttraumatic stress between elderly and younger residents. Psychiatry. 68(2), 164-173.

Gaskell, S. L., Wells, A., \& Calam, R. (2001). An experimental investigation of thought suppression and anxiety in children. British Journal of Clinical Psychology, 40, 45-56.

Kendall, P. C. (1985). Toward a cognitive-behavioural model of child psychopathology and a critique of related interventions. Journal of Abnormal Child Psychology, 13, 357-372.

Kendall, P. C., Chansky, T. E., Kane, M. T., Kim, R. W., Kortlander, E., Conan, K. R., Sessa, F. M., \& Siqueland, L. (1992). Anxiety disorders in youth: Cognitive behavioral interventions. Needham Heights, MA: Allyn \& Bacon.

Leaver, T. (2006). iTeach, iLearn: Student podcasting (The Presentation), Tama's Elearning Blog. Retreived 5 March 2006 from http://tama.edublogs.org/2006/02/03/iteach-ilearn-student-podcasting-thepresentation/

Morrison, A.P., Haddock, G., \& Tarrier, N. (1995). Intrusive thoughts and auditory hallucinations: A cognitive approach. Behavioural and Cognitive Psychotherapy, 23, 265-302.

Pennebaker, J. W. (1993). Putting stress into words: Health, linguistic, and therapeutic implications. Behavioral Research Therapy, 31, 539-548. 
Pennebaker, J. W., \& Beall, S. (1986). Confronting a traumatic event: Toward an understanding of inhibition and disease. Journal of Abnormal Psychology, 95, 274-281.

Pennebaker, J., Mayne, T., \& Francis, M. (1997). Linguistic predictors of adaptive bereavement. Journal of Personality and Social Psychology, 72, 863-871.

Posey, T. B., \& Losch, M. E. (1983). Auditory hallucinations of hearing voices in 375 normal subjects. Imagination, Cognition and Personality, 2, 99-113.

Salkovskis, P. M. (1985). Obsessive-compulsive problems: A cognitive-behavioural analysis. Behaviour Research and Therapy, 23, 571-583.

Sarason, I. G. (1984). Stress, anxiety and cognitive interference: reactions to tests. Journal of Personality and Social Psychology, 46, 929-938.

Sarason, I. G. (1988). Anxiety, self-preoccupation and attention. Anxiety Research, 1, 3-7.

Sarason, I. G., Sarson, B. R., \& Pierce, G. R. (1990). Anxiety, cognitive interference, and performance. Journal of Social Behavior and Personality, 5, 1- 18.

Slade, P. D., \& Bentall, R. P. (1988). Sensory deception: A scientific analysis of hallucination. London: Croom Helm.

Smyth, J., \& Pennebaker, J. (1999). Telling one’s story: Translating emotional experiences into words as a coping tool. In C. R. Snyder (Ed.), Coping: The psychology of what works (pp. 70-89). New York: Oxford University Press.

Smyth, J., True, N., \& Souto, J. (2001). Effects of writing about traumatic experiences: The necessity for narrative structuring. Journal of Social and Clinical Psychology, 20(2), 161-172.

Strauss, J. S. (1969). Hallucinations and delusions as points on continua function: Rating scale evidence. Archives of General Psychiatry, 21, 581-586.

Walker, J., \& Boyce-Tillman, J. (2002). Music lessons on prescription? The impact of music lessons for children with chronic anxiety problems. Health Education, 102(4), 172-179.

\section{Biography}

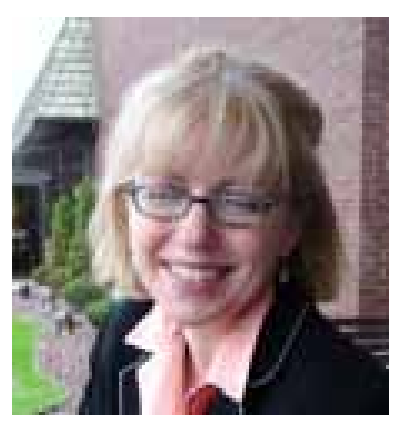

Susan Smith Nash has been involved in the design, development and administration of online courses and programs since the early 1990s.

Her current research interests include the use of learning objects, new, popular technologies in distributed education, and leadership in elearning organizations. Her articles and columns have appeared in journals, and her podcasts and articles on e-learning can be found online in educational weblogs. She received her Ph.D. from the University of Oklahoma in 1996, and in addition to e-learning, Nash has also been involved in international economic development training, and humanities and culture, which has included the promotion of Slovenian literature. Her latest books include Lonelyhearts Pawn Shop, published by Light \& Dust Books, and Otozna Boginja, published by Vodnikova Zalozba (Ljubljana). Her book, Leadership in the e-Learning Organization, is forthcoming. 